J. Natn. Sci. Coun. Sri Lanka 1997 25(2): 105-112

\title{
AGROBACTERIUM TUMOURS IN KAPOK (CEIBA PENTANDRA L.) IN SRI LANKA
}

\author{
J.M.R.S. BANDARA and J.M.D. BANDARA \\ Department of Agricultural Biology, Faculty of Agriculture, University of Peradeniya. \\ Peradeniya.
}

(Received: 26 October 1996: accepted: 07 March 1997)

\begin{abstract}
Natural infections by Agrobacterium tumefaciens causing oncogenic crown gall tumours were observed in fast growing Ceiba pentandra var. pentandra (Kapok) in the cooler areas of the wet zone of Sri Lanka. Knotty tumours often reached $30-40 \mathrm{~cm}$ in diameter. Infected plants remained stunted. Natural spread of the disease appeared to be vertical even in a congregation of Kapok trees. Kapok isolates were studied in comparison to C58, Ach5 and T37. Kapok isolate was similar to Biovar 1 and was found to be pathogenic to tomato, brinjal, chilli and tobacco.
\end{abstract}

Key words: Agrobacterium, Ceiba pentandra, crown gall, kapok.

\section{INTRODUCTION}

Crown gall disease caused by Agrobacterium tumefaciens has a world wide distribution $^{1}$ and was locally observed as crown gall formation in Ceiba pentandra var. pentandra (Kapok). Kapok is a fast growing deciduous tree commonly grown as a shade tree for cacao and as a live support to Piper nigrum in mixed home gardens. Kapok fruits produce floss of cotton-like fibre that is used in industry as heat insulators and in packing cushions and furniture. The soil borne plant pathogen, Agrobacterium tumefaciens causes a neoplastic disease crown gall by transferring a segment of bacterial DNA viz. T-DNA to the plant genome. Expression of bacterial T-DNA in transformed plant cells produces uncontrolled, undifferentiated lump of oncogenic cells resulting in a crown gall tumour that synthesizes opines. Opines are beneficial only to Agrobacterium tumefaciens. Crown gall is characterized by unlimited cell proliferation, which may lead to regression or death of the plant. Crown gall tumours vary considerably in their morphology. ${ }^{2}$ The disease has been studied extensively ${ }^{3-6}$ and several reviews have been published..$^{1,7,8}$

\section{METHODS AND MATERIALS}

Samples were collected from fresh tumours in naturally infected Kapok plants Ceiba pentandra var. pentandra. Standard cultures of A.tumefaciens C58, Ach5 and T37 were kindly supplied by Prof. Gunter Kahl, Frankfurt am Main, Germany. 
Test for tumour induction ability: Excised tissue from fresh (white) tumour was diced into about $5 \mathrm{~mm}$ cube pieces, surface sterilized with $0.01 \%$ mercuric chloride for 1-2 min and rinsed thoroughly with sterile distilled water. Surface sterilized tumour portions were placed on phytohormone-free MS medium ${ }^{9}$ containing carbenicillin $(500 \mathrm{mg} / 100 \mathrm{ml})$ in culture tubes. Similar inoculations were done on to hormone-free MS medium without carbenicillin and also on to carbenicillin free nutrient agar. Each treatment was replicated ten times and incubated at $25^{\circ} \mathrm{C}$ under $12 \mathrm{~h}$ illumination cycle of 1300 lux.

Isolation of pathogen: Pathogen was isolated from washed gall tissue on KadoHeskett D1M selective medium. ${ }^{10}$ Tumour tissues were surface sterilised with $0.1 \%$ mercuric chloride for a period of one minute and rinsed well in sterile distilled water. Tissue was then diced into smaller pieces of $2 \mathrm{~mm}$ square under aseptic conditions and placed in $2 \mathrm{ml}$ of sterile distilled water. Suspension was then allowed to stand for $30 \mathrm{~min}$ before streaking on Kado -Heskett D1M selective medium. Purified bacterial cultures were maintained in YBP medium (yeast extract $1.0 \mathrm{~g}$, beef extract $5.0 \mathrm{~g}$, peptone $5.0 \mathrm{~g}$, sucrose $5.0 \mathrm{~g}$, magnesium sulphate $0.5 \mathrm{~g} / \mathrm{l}$ at $\mathrm{pH}=7$ ) at $25^{\circ} \mathrm{C}$.

Pathogenicity test: Anderson \& Moore ${ }^{11}$ reported that host specificity is the rule among strains of Agrobacterium and that no host is infected by more than $81 \%$ of the pathogenic strains. The host range of a strain is not determined by the plant from which the pathogen is isolated. Pathogenicity tests were done by wound inoculation of 2-6 wks old healthy seedlings, at about $3 \mathrm{~mm}$ above the first leaf axil of Ceiba pentandra var. pentandra, Lycopersicon esculentum CV. Katugastota, Capsicum annuum CV. MI2, Allium cepa, Oryza sativa cv BG450 and Chrysanthemum. All seedlings were raised from surface sterilized seeds in the plant house at $25 \pm 2^{\circ} \mathrm{C}$. Seedlings were grown in polyshine paper cup $(7 \mathrm{~cm}$ diameter) containing either sterile soil or vermiculite as three seedlings per pot. Thirty seedlings were used for each treatment. Thirty uninoculated seedlings were maintained in ten pots on both substrates from each of the species as control. Standard strain C58 was used as a check strain. Number of seedlings that produced tumours were recorded and data were analyzed using t test and least significant difference test.

Agrobacterium tumefaciens Kapok isolates were differentiated from other standard isolates using 3-ketoglycoside test ${ }^{12}$ and acid production ability in erythritol. ${ }^{13}$ Growth curve of the Kapok strain in Kado broth ${ }^{10}$ was established by plotting cell number versus time using McFarland scale. ${ }^{14}$ Bacteria were grown in $25 \mathrm{ml}$ of Kado broth in $250 \mathrm{ml}$ Erlenmeyer flasks with continuous shaking in a rotary shaker. Medium was inoculated with $0.1 \mathrm{ml}$ of starter cultures (about $48 \mathrm{~h}$ old) diluted 100 fold to obtain $105-106 \mathrm{cells} / \mathrm{ml}$. The absorbance values of the cultures were measured half hourly using a spectrophotometer at $620 \mathrm{~nm}$. Values were converted to cell number using McFarland scale. 


\section{RESULTS AND DISCUSSION}

Agrobacterium tumours in Kapok were observed only in the wet zone of Sri Lanka. We observed that Kapok tends to grow in congregation in wild and when Agrobacterium infections were observed almost all the trees had prominent tumours. The spread of the tumours was more prominent in a vertical distribution (Fig.1).

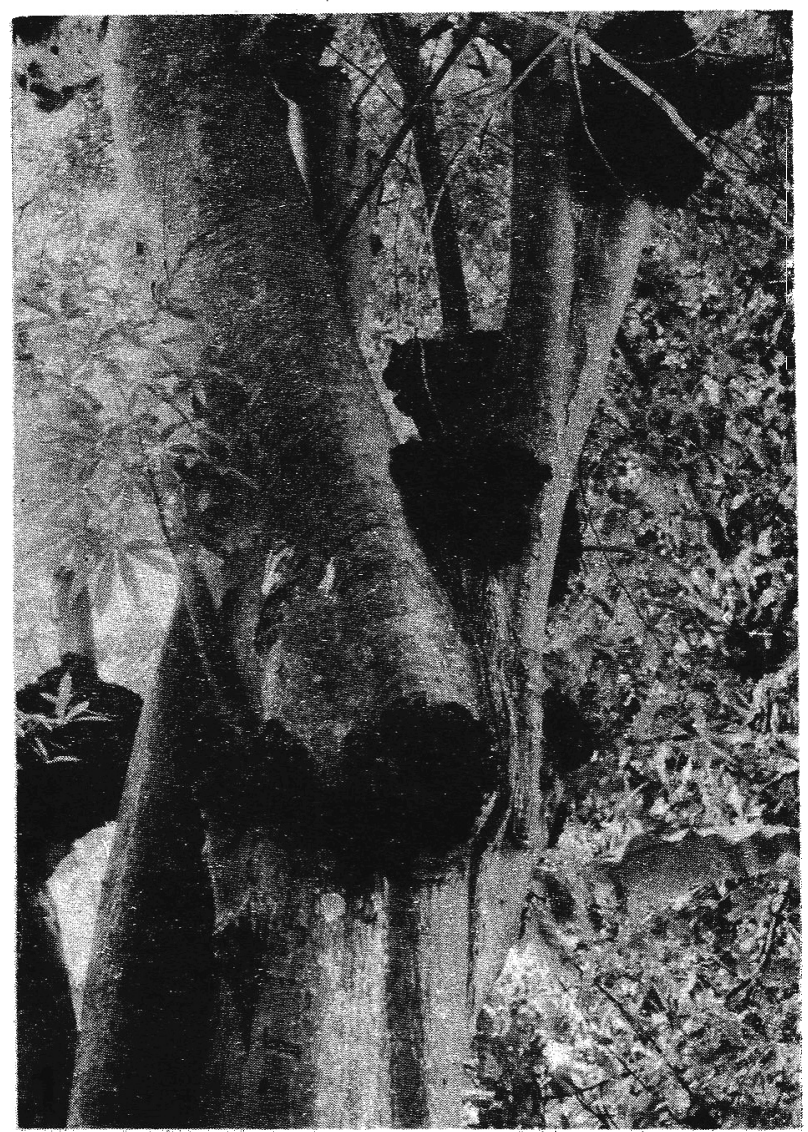

Figure 1: Distribution of Agrobacterium tumours on a naturally infected Kapok (Ceiba pentandra) tree.

Agrobacterium tumours on kapok usually appear as a small overgrowth on the stem particularly near the soil line. At the very early stages of development tumours were spherical, soft in texture and creamy white in appearance (Fig.2). As the tumours enlarged, the peripheral cells of the convoluted outer tissues died and decayed to form a brown or black crust. Due to the faster growth habit of Kapok, the tumours quickly grew bigger along with the increase in girth of the stem and often the knotty tumours reached about 30-40 cm diameter (Fig. 1). Crown gall affected plants remained stunted in comparison to healthy plants of the same age. 


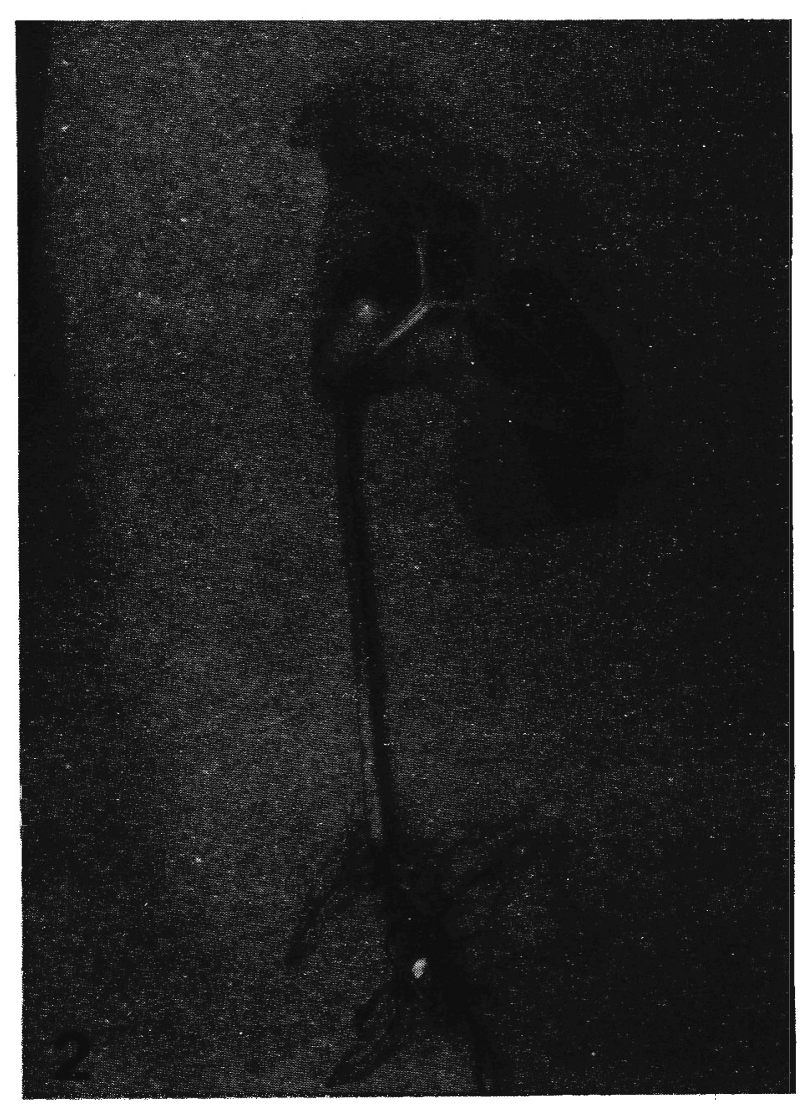

Figure 2: Creamy white tumour produced on Kapok seedling artificially inoculated with locally isolated AB/Kapok strain of Agrobacterium tumefaciens.

Pathogen was isolated from washed, healthy, white gall tissue on KadoHeskett $\mathrm{D}^{1} \mathrm{M}^{10}$ selective medium. Cultures were restreaked on YEB medium to obtain single cell colonies. Colonies of Agrobacterium tumefaciens on D1M medium initially appeared greenish blue and turned dark green with time. Kado - Heskett D1M medium selects strains of both biovar I and II of Agrobacterium. ${ }^{15}$ However Lippincott et al. ${ }^{16}$ reported that D1M medium of Kado \& Heskett ${ }^{10}$, supported colony formation of biovar I strain with high efficiency. The maximum growth temperature that could be tolerated by biovar I bacteria of Agrobacterium is reported to be $37^{\circ} \mathrm{C}$ compared to $29^{\circ} \mathrm{C}$ for biovar II. Panagopoulos \& Psallidas ${ }^{17}$ showed that many Agrobacterium strains show little growth above $29^{\circ} \mathrm{C}$. Dicky ${ }^{18}$ reported that survival of Agrobacterium was reduced in acid soils. T-DNA transfer to plant subsequent to oncogenic activity is reported to be interrupted at about $30^{\circ} \mathrm{C} .{ }^{16}$ This probably limits the distribution of the disease in warmer wet zone areas and dry zone of Sri Lanka. 
Isolates obtained when differentiated using 3-ketoglycoside test showed a significant yellow ring of $\mathrm{Cu}_{2} \mathrm{O}$ indicating the 3-ketolactose production by the test strains. Rate of 3-ketolactose production varied with the cultures tested. The mean time taken in minutes for the appearance of yellow ring - the expression of ketolactose production by the strains are T 37: $16 \mathrm{~min}, \mathrm{C} 58: 20 \mathrm{~min}$, Ach 5: $25 \mathrm{~min}$ and $\mathrm{AB} / \mathrm{Kapok}: 12 \mathrm{~min}$.

Significant reddish brown pellicle formation on ferric ammonium citrate broth $^{19}$ incubated in stationary culture tubes and clear absence of acid production from erythritol indicated that the Kapok isolate behaves similar to those of biovar I. ${ }^{15,16}$

Tumour induction ability: Seventy three percent of the tumour portions transferred to carbenicillin and cefatoxime containing hormone-free MS medium initiated callus growth in 6-7 days and showed prominent callus growth in 3 weeks (Fig.3). However about $40 \%$ of the treatments showed prominent callus growth in the absence of hormones and carbenicillin. The carbenicillin-free medium, however, was soon overgrown by the pathogen and as such it was not maintained for more than 7 days.

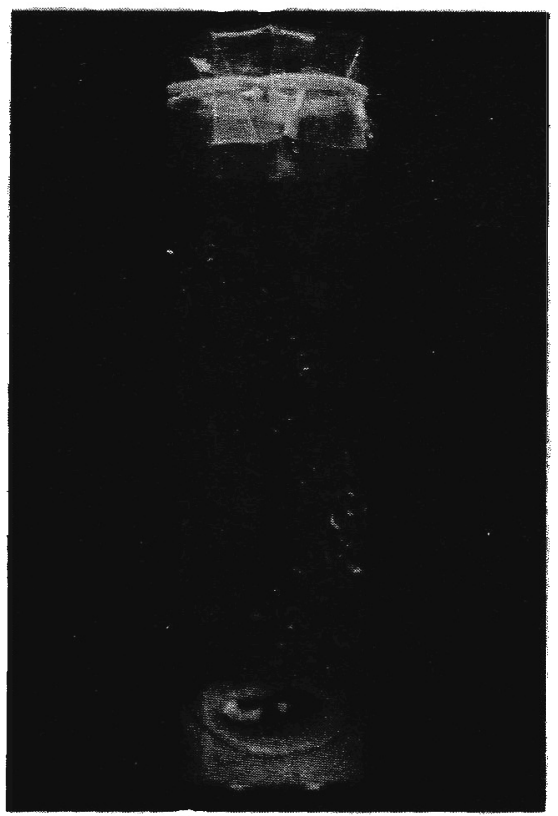

Figure 3: Callus growth from natural tumour portion transferred to carbenicillin and cefatoxime containing hormone-free MS medium.

Tumour induction ability on artificial inoculations of Kapok seedlings is summarized in Table 1. 
Table 1: Tumour induction response in Agrobacterium tumefaciens inoculated Kapok seedlings. ${ }^{a}$

\begin{tabular}{lcc}
\hline Strain & Percentage of Tumour producing seedlings \\
& 7 DAI & 14 DAI \\
\hline Control $^{\mathrm{b}}$ & $0 \mathrm{x}$ & $0 \mathrm{x}$ \\
C 58 & $20 \mathrm{y}$ & $70 \mathrm{y}$ \\
AB/Kapok & $30 \mathrm{y}$ & $90 \mathrm{z}$ \\
\hline
\end{tabular}

Values followed by the same letter in each column are not significantly different at $\mathrm{P}=0.05$.

a 30 seedlings were inoculated in Polyshine paper cups, 3 seedlings per cup.

${ }^{b}$ Uninoculated control

DAI = Days after Inoculation

The tumours produced by $\mathrm{AB} / \mathrm{Kapok}$ strain were smooth and relatively larger in size than C58 (Fig. 4).

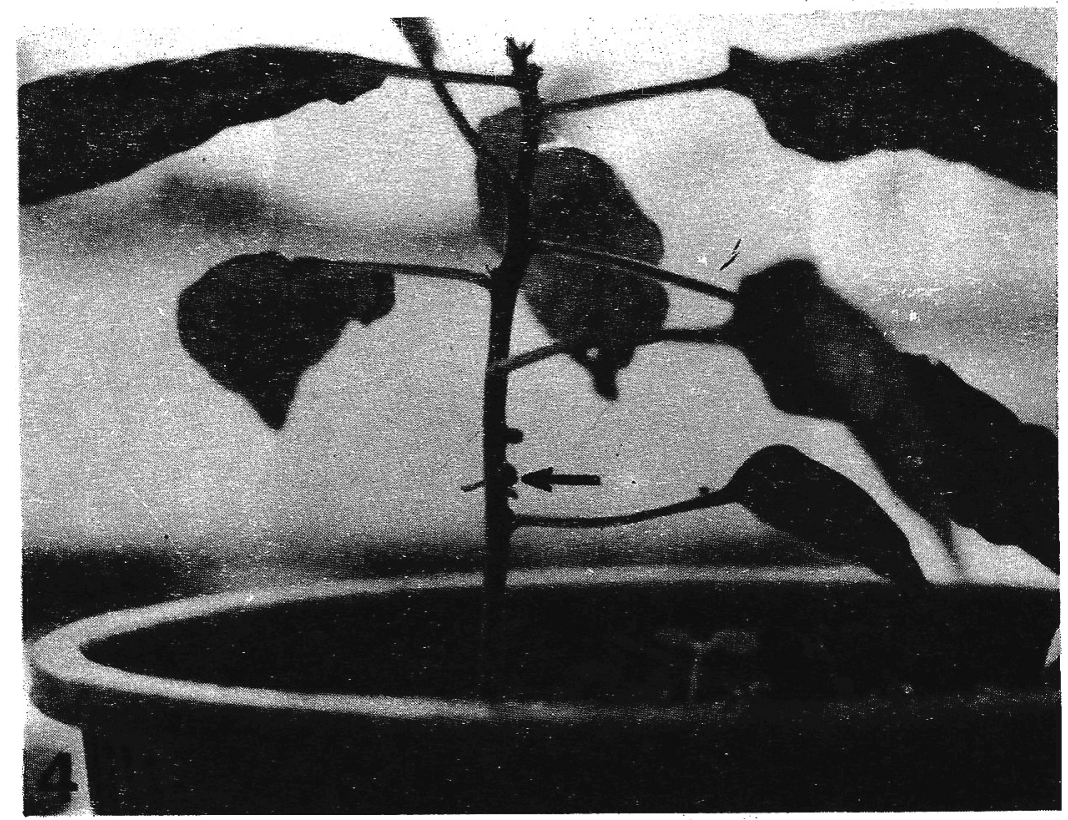

Figure 4: Tumour production (arrow) in a chilli plant artificially inoculated with $\mathrm{AB} / \mathrm{Kapok}$ strain.

Pathogenicity of Kapok strain to other crops: Among brinjal, chilli, tomato, groundnut, chrysanthemum, onion and rice, only tomato, brinjal, chilli and tobacco responded positively to inoculation by producing smooth tumours on seedlings. Although chrysanthemum, groundnut, onion and rice did not produce 
tumours on inoculation we were unable to rule out possible infection as callus induction could take a very long period of time. Dommisse et al. ${ }^{20}$ reported that onion takes six to seven weeks and roses 18 months to produce symptoms after inoculation with Agrobacterium tumefaciens. In this study three weeks old seedlings of tomato, tobacco, chilli and brinjal showed visible tumour growth $7,9,44$ and $52 \mathrm{~d}$ after inoculation, respectively. The significance of our observations is that crown gall could spread among fast growing forest trees in the wet zone particularly in the Mahaweli catchment areas where Kapok occurs in congregations. Besides, in cooler areas it could well be a pathogen that needs to be of concern.

\section{Acknowledgement}

Financial support provided to JMRSB from Council for Agricultural Research Policy is gratefully acknowledged.

\section{References}

1. Drummond M. (1983). Crown gall disease: a case study. In: Biochemical plant pathology (Ed. J.A.Callow). pp. 65-74. John Wiley \& Sons. London.

2. Hooykaas P.J.J., Klapwijk P.M., Nuti M. P., Schilperoort R.A. \& Rorsch A. (1977). Transfer of the Agrobacterium tumefaciens Ti plasmid to avirulent Agrobacteria and Rhizobium ex planta. Journal of General Microbiology $\mathbf{9 8}$ : 477-484.

3. Ark P.A. \& Sibray W.S. (1957). Efforts to control crown gall of roses with antibiotics. Plant Disease Reporter 41: 449-451.

4. New P.B. \& Kerr A. (1972). Biological control of crown gall. Field measurements and glass house experiments. Journal of Applied Bacteriology 35: 279-282.

5. Lippincott J.A. \& Lippincott B.B. (1975). Morphogenic determinants as exemplified by the crown gall disease. In: Physiological plant pathology (Eds. R. Heitefuss \& P.H. Williams) pp. 356-388. Springer-Verlag, New York.

6. Kerr A. \& Panagopoulos C.G. (1977). Biotypes of Agrobacterium radiobacter var. tumefaciens and their biological control. Phytopathologische Zeitschrift 90: 172-179.

7. Nester E.W., Gordon M.P., Amasino R.M. \& Yanofsky M.F. (1984). Crown gall: molecular and physiological analysis. Annual Review of Plant Physiology 35: 387-413. 
8. Hooykaas P.J.J. \& Beijersbergen A.G.M. (1994). The virulence system of Agrobacterium tumefaciens. Annual Review of Phytopathology 32: 157-180.

9. Murashige T. \& Skoog F. (1962) A revised medium for rapid growth and bioassay with tobacco tissue culture. Physiologia Plantarum 15: 473-497.

10. Moore L.W., Anderson A.R. \& Kado C.I. (1980). Gram negative bacteria: Agrobacterium. In: Laboratory manual for identification of plant pathogenic bacteria. (Ed. N.W.Schaad) pp. 17-25. The American Phytopathological Society, Minnesota.

11. Anderson A.R. \& Moore L.W. (1979). Host specificity in the genus Agrobacterium. Phytopathology 69: 320-323.

12. Bernaerts M.J. \& De Ley J. (1963). A biochemical test for crown gall bacteria. Nature 197: 406-407.

13. Hayward A.C. (1964). Characteristics of Pseudomonas solanacearum. Journal of Applied Bacteriology 27: 265-277.

14. Kiraly Z. (1974). Methods in plant pathology. Elsevier Scientific Publishing Company, London.

15. Keane P.J., Kerr A. \& New P.B. (1970). Crown gall of stone fruit II. Identification and nomenclature of Agrobacterium isolates. Australian Journal of Biological Science 23: 585-595.

16. Lippincott J.A., Lippincott B.B. \& Starr M.P. (1981). The genus Agrobacterium. In: The Prokaryotes Vol I. (Eds. M. P. Starr, H.G. Truper, A. Balows \& H. G. Schlegel) pp. 843-855. Springer Verlag, New York.

17. Panagopoulos C.G. \& Psallidas P.G.(1973). Characteristics of Greek isolates of Agrobacterium tumefaciens. Journal of Applied Bacteriology 36: 233240 .

18. Dickey R.S. (1961). Relation of some edaphic factors to Agrobacterium tumefaciens. Phytopathology 51: 607-614.

19. Hendrickson A.A., Baldwin I.L. \& Riker A.J. (1934). Studies on certain physiological characters of Phytomonas tumefaciens, Phytomonas rhizogenes and Bacillus radiobacter II. Journal of Bacteriology 28: 597-618.

20. Dommisse E.M., Leung D.W.M., Shaw M.L. \& Conner A.J. (1990). Onion is a monocotyledonous host for Agrobacterium. Plant Science 69: 249-257. 